\title{
Study on Hainan Rural Tourism under Perspective of Low Carbon Economy
}

\author{
Shibiao Lei \\ Haikou College of Economics, Haikou, Hainan, 571127
}

Keywords: Perspective of low carbon economy; Rural area in Hainan, Tourism development

\begin{abstract}
. low carbon economy conforms to sustainable development concept, and it is beneficial to economic development and social progress. Under the perspective of low carbon economy, development of rural tourism is beneficial to promoting long-term development of rural tourism. Hainan is an ocean island with rich resources. It develops increasingly well in rural tourism. This paper analyzes the problems in development of rural tourism and advantages of rural tourism development under the perspective of low carbon economy. Besides, this paper further proposes how to better develop rural tourism in Hainan, do planning well, highlight advantages of Hainan, enhance infrastructure construction and develop rural tourism under the precondition of sustainable development so as to make Hainan go farther on rural tourism road.
\end{abstract}

\section{Introduction}

China always pays attention to tourism of Hainan and continuously comes up with policies to help Hainan develop tourism. Rural tourism becomes more and more popular. People start to like to taste green food of peasant families, fall asleep in peasant families and do farm work to feel the joys of laboring. Rural tourism has become one of increasing popular traveling forms. Hainan as a unique island has huge advantages in rural tourism. But, some problems exist in the process of developing rural tourism, such as waste of resources and damage to environment. This is not a long-term strategy. Development of rural tourism from the perspective of low carbon economy is beneficial to improving current situation.

\section{Overview of low carbon economy}

Low carbon economy pursues green and non-pollution and development of economy under the precondition of consuming few resources. Low carbon economy follows sustainable development idea, and strives to develop new energy and renewable energy, transform industrial type and create new system, science and technology so as to consume less energy and especially carbon dioxide, reduce emotion of noxious gas leading to greenhouse effect, promote economic development, social progress and favorable ecological environment. To promote the development of low carbon economy, it is necessary to undertake the heavy burden of preserving the ecological environment, change previous economic structure and better utilize limited resources. Economic development should not be hindered, and serious damage and pollution should not be caused to the environment.

\section{Analysis of rural tourism idea}

Rural tourism utilizes rural natural landscape and human landscape to attract tourists. It mainly depends on natural landscape including lake, river, brook and mountain as well as characteristic structures and cultural conventions of local rural area. Tourists can participate in recreational activities in rural area and enjoy the scenery in rural area, like taking a holiday. Rural tourism generally includes folk customs with local rural characteristics to make tourism richer. As rural tourism operators, peasants offer houses for tourist and food and allow tourist do some housework, such as cutting firewood, pasturing cattle and harvesting so that tourist can enjoy joys in rural area. Rural tourism is mainly oriented to urban residents. They live intense and nervous urban life. For 
them, rural area is like a land of idyllic beauty, far away from noises and business. They enjoy relaxing and pleasant rural life and feel pure, plain and enthusiastic characters of rural people.

Rural tourism includes many different types according to functions and contents. Rural tourism can make tourists visit and enjoy natural scenery and rural buildings as well as performance activates with folk customs. Rural tourism can make tourist taste delicious food with rural characteristics. Tourists may pick up green vegetables or fruit beside fruit trees. Besides, tourists may plant vegetables and trees, harvest rice or irrigate farmland. Except these, they may herd sheep, pasture cattle or carry water and cut firewood. Through these practical activities, tourist can learn relevant knowledge of agricultural production. Rural tourism can provide heath maintenance activities for tourists, such as taking a bath in hot spring. Rural tourism can let tourists feel local breath and feeling rural humanistic style and rural traditional culture through taking culture as the theme. Rural tourism can gather multiple functions and offer tourists with all-round travelling experience. Tourists can view scenery, taste food, experience farm work, have a rest, maintain health and feel culture.

\section{Beneficial functions of tourism development under the perspective of low carbon economy}

Under the perspective of low carbon economy, tourism development is beneficial to improving global warming. Nowadays, global warming is a world topic. Each country strives to relieve global warming issue. Climate of each country starts to become warmer and warmer. The temperature in winter is not as cold as before. Ice and snow thaw and flow into the ocean. The coastline approaches mainland little by little. Sand storm become further serious. Deserts become more and more. The weather changes unpredictably. Air temperature is either hot or cold. Ecological environment is seriously damaged. This hinders tourism development. Under the perspective of low carbon economy, it is required to make efforts to relieve greenhouse effect and solve global warming problem. Low-carbon tourism development is tourism development on the basis of reducing consumption of carbon emission and beneficial to improving climate warming. China's economic development is still at the cost of polluting the environment, developing industries with high carbon emission and consuming many non-renewable energy sources. Development of low-carbon economic tourism is a new tourism reform. It changes traditional tourism production form and caters to new economic development form. Tourism emits much carbon which pollutes environment. Tourism development under the perspective of low carbon economy contributes to saving limited resources and conducting sustainable utilization and development.

\section{Advantages of Hainan rural tourism development under the perspective of low carbon economy}

Under the perspective of low carbon economy, Hainan began to build civilized ecological villages from 2000. Through ten-year efforts, an ecological village with certain scale has been built. From continuous rise in the number of ecological villages to improvement of quality of ecological villages, Hainan has made many contributions to ecological village. Through construction of these, rural environment of Hainan becomes better, and economic development is faster. Rural appearance becomes cleaner. These are beneficial to development of rural tourism. Hainan is a tropical zone and develops well in agricultural development. China also provides much support for tourism development. Hainan is not just a tropical zone, but also the sole ocean island with tropical climate. It owns various tropical resources. Hainan does not lack fruits, marine products, flowers and green vegetables.

Especially in winter, Hainan's climate is very warm, like "spring” in winter. People all over the country will swarm into Hainan in cold winter to spend a warm winter. Hainan is a very large ocean island and owns Oceanside villages with characteristics. Hainan villages own beautiful seascape, including sandbeach, seawater, small island and coconut grove. The air there is very clean, and islet is cool and pleasant. The sky is azure blue. There is also miraculous selva, seabed diving and ocean world. Hainan villages include about 30 nationalities. Each nationality has its own customs. Their 
dance, sings, music, dressing, delicious food and festival celebration are attractive points of rural tourism. Hainan is also a green rural tourism. Under low carbon economy, it is almost free from pollution.

\section{Problems in rural tourism development}

Although Hainan owns many advantages in rural tourism development and does well, some problems still exist. Hainan's economic level is not high. The government cannot input ample funds to construct rural infrastructure such as electricity, water, communication and health. In terms of traffic, trains are few, and buses are few. Rural tourism operators drive cars to pick up tourists. Corresponding accommodation conditions are poor. Although there are some five-star luxury hotels, construction of most hotels is not very good. Catering, delicious food, leisure and recreation are not very perfect. These are adverse to development of rural tourism.

Hainan region is closed and contacts less with the external world. Information flow and update are slow. Cultural level of local rural people is low. They seldom cognize rural tourism development and fail to establish advanced tourism idea. As the tourists become more and more, tourists' educational level becomes increasingly high. The tourists from other countries also increase. Rural residents cannot provide high-quality services for them. In addition, traveling places are violently built in order to attract more tourists in current rural tourism development. Primitive villages are developed continuously. There is short of rational planning and management in the development process. Thus, many resources are wasted. At the same time, the environment is damaged. Current rural tourism development still stays at a low level. Tourism products are not plentiful. Only superficial tourism resources are developed, without deep excavation. Although Hainan rural tourism owns many advantages, publicity work is not done well in the development process. Many tourism products are not known by others. No international brand forms.

\section{Measures to develop Hainan rural tourism under the perspective of low carbon economy}

\section{Do planning well}

Under the perspective of low carbon economy, the development of Hainan rural tourism industry cannot be conducted blindly. It should be conducted on the basis of planning. Planning is the foundation of tourism development. Villages in Hainan own characteristics. Each village has its own characteristics. During development of rural tourism, all villages should not swarm. Rational planning should be done well. To plan rural tourism, it is necessary to plan each element such as agriculture and environment. During planning the regions, geographical conditions differ greatly. The resources in the south and north are also diverse. Thus, it is necessary to divide different resources in line with different regions. A corresponding theme can be found in rural tourism in each region. It is required to avoid repeated rural tourism themes. Furthermore, it is also necessary to discover and organize bad competitions of rural tourism. During planning tourism paths, it is necessary to list scenic spots with the highest value in Hainan and form an all-round tourism network according to characteristics or territory.

\section{Highlight local advantages of Hainan}

Under the perspective of low carbon economy, Hainan's unique advantages should be considered in order to perfect development of Hainan rural tourism. Hainan owns advantages in development of rural tourism, such as flower, food, marine products, fruit and green vegetables. Besides, Hainan is building agricultural center in tropical zone. So, larger advantages will emerge. Hence, during development of rural tourism, advantages of Hainan should serve as key development objects. Of course, traditional development path is of no attraction. To better give play to advantages of Hainan rural tourism, it is necessary to confirm to market requirements, increase technical content of rural tourism products, do rural tourism more finely and enhance quality of agricultural products. Beautiful environment and rich resources are the key points of rural tourism development in Hainan. Of course, resource protection should be valued during highlighting advantages. Advantages should not become disadvantages in immoderate development. For the villages with many advantages, they should be developed first. For the villages with few advantages, they should be developed within proper range. 
Especially for rural scenic spots where ecological environment may be easily damaged and resources and environment own very high value, they should not be developed for the time being, but should be protected.

\section{Enhance infrastructure construction}

Under the perspective of low carbon economy, Hainan should enhance rural infrastructure construction. Firstly, train routes and bus routes may be constructed in rural tourism places. Traffic connection among Sanya, Haikou and other cities should increase. In addition, navigation routes between small islands of rural scenic spots and main islands of Hainan should increase. Secondly, water supply facilities and power supply facilities in rural scenic spots should be enhanced. Drinking water quality should improve. Power supply base stations and electric wire facilities should rise. Management and maintenance of water supply and power supply facilities should electric wire. In addition, communication and network also need to strengthen. Signal stations of China Mobile, China Unicom and China Telecom should increase. Communication facilities construction should be enhanced. Thus, it is necessary to cooperate between the government and communication companies. Network is very important for rural tourism. Now, many tourists almost cannot live without network. Poor network will seriously affect traveling quality and reduce the number of tourists. Accommodation facilities also should be enhanced. Nowadays, accommodation conditions in many visages are not very good. Poor accommodation conditions are adverse to development of rural tourism. For accommodation, Hainan should improve basic accommodation facilities based on keeping original rural features. Under the precondition of no damage to characteristics of peasant households, convenient and comfortable accommodation environment should be provided for tourist. Meanwhile, some villas may be built for tourists with high requirements.

\section{Conclusions}

With tourism development and increasingly large urban pressure, people gradually turn to rural tourism from urban tourism. People increasingly like to feel pure and plain village life, feel beautiful nature, pick up vegetables and fruit, participate in village labor, taste green food and relieve pressure and tension in rural area. Hainan as an ocean island with rich resources and favorable geographical environment is favored by both domestic and international people. But, Hainan also has some problems in development of rural tourism. It is necessary to seek improvement measures from the perspective of low carbon economy. Through efforts in various aspects, Hainan rural tourism development will be done better and better.

\section{Acknowledgments}

This paper gains the subsidy of the topic of Haikou College of Economics "study on development of low carbon tourist economy in Hainan International Tourism Island construction"; topic No.: Hjky13-07.

\section{References}

[1] Yu Meizhu, Study on Heisey tourism development under the background of tourism development - case study of rural tourism development in Jianning County of Fujian Province. Journal of Yunnan Agricultural University, 2011, 5(6): 33-35.

[2] Hou Peixun, Fan Shichen, Study on development of Hainan tourism development under the background of international tourism island. Collective Economy, 2011(06): 139-140.

[3] Bo Motianfu, An Yufang, Study on Hainan rural tourism development under the perspective of international tourism island. Journal of Qiqihar Junior Teachers' College, 2011 (02): 92-93. 
[4] Yu Tian, Problems and countermeasures of accommodation in rural tourism under the perspective of low carbon economy - case study of Guizhou province. Managers' Journal, 2013(09): 34-36. 